
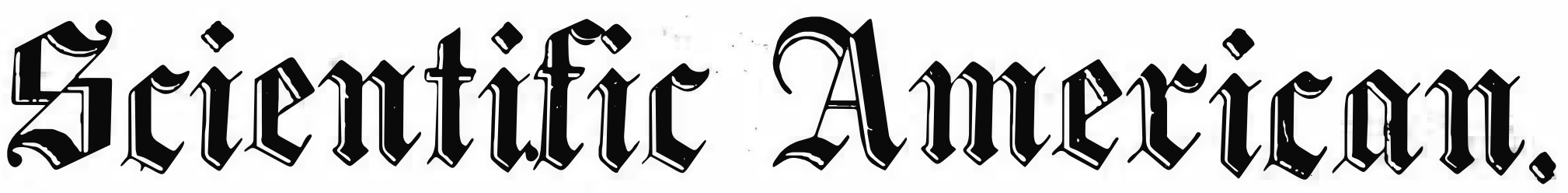

THE ADVOCATE OF INDUSTRY, AND JOURNAL OF SCIENTIFIC, MECHANICAL AND OTHFR IMPROVEMTENTS.

bol. h.

New Whork, Jamuarw $13,185 \mathfrak{s}$.

No. 17.

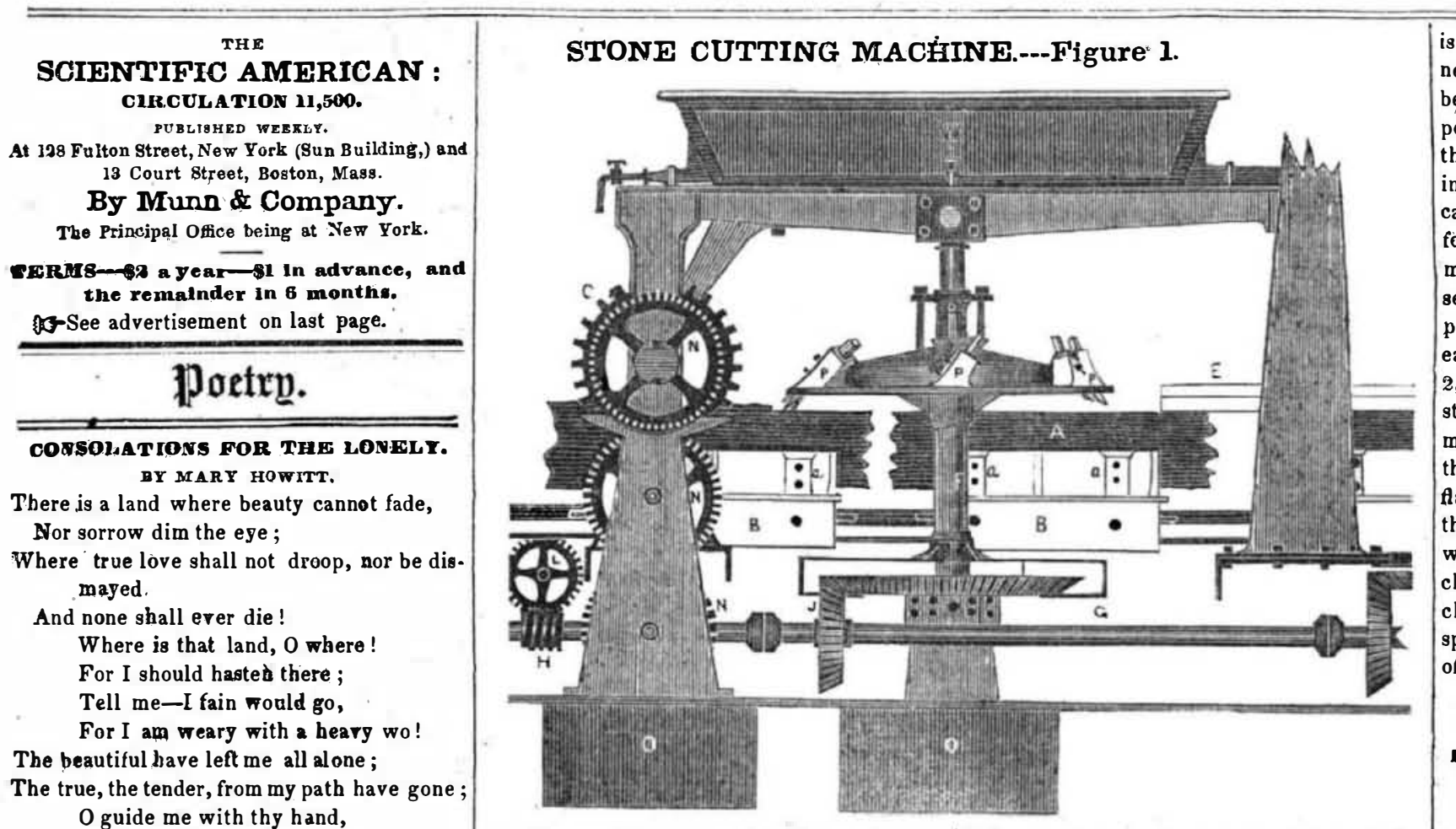

0 guide me with thy hand,

If thou dost know that land,

For when burthened with oppressive care,

And I am weak and fearful with despair ;

Where is it? Tell me where.

Friend thou must trust in him who trod before

The desolate paths of life;

Must bear in meekness as he meekly bore,

Sorrow ard pain, and strife

Think how the Son of God

These thorny patks hath trod

Think how he longed to go,

Yet tarried out for thee the appointed wo.

Think of his weariness in places dim,

Where no man comforted or cared for him !

Think of the blood-like sweat,

With which his brow was wet

Yet how be prayed unaided and alone,

In that great agony, " Thy will be done !"

Friend do not thou despair

Christ, from the hearen of heavens will hear

thy prayer!

THE PATHERLESS.

" Speak softly to the fatherless

And check the harsh reply

That sends the crimson to the cheek,

The tear-drop to the eye.

They have the weight of loneliness

In this rude world to bear;

Then gently raise the fallen bud,

The drooping flowerets spare.

Speak kindly to the fatherless!

The lowliest of their band

God keepeth, as the waters,

In the hollow of his hand.

'Tis sad to see life's evening sun

Go down in sorrow's shroud,

But sadder still when morning's dawn

Is darkened by the cloud.

Look mildly on the fatherless

Ye may have power to wile

Their hearts from sadden'd memory

By the rnagic of a smile.

Deal gently with these little otes

Be pitiful, and $\mathrm{He}$

The friend and father of us all,

Shall gently deal with thee !'

Mr. and Mrs. Randall, the celebrated Scotch

Figure 2.

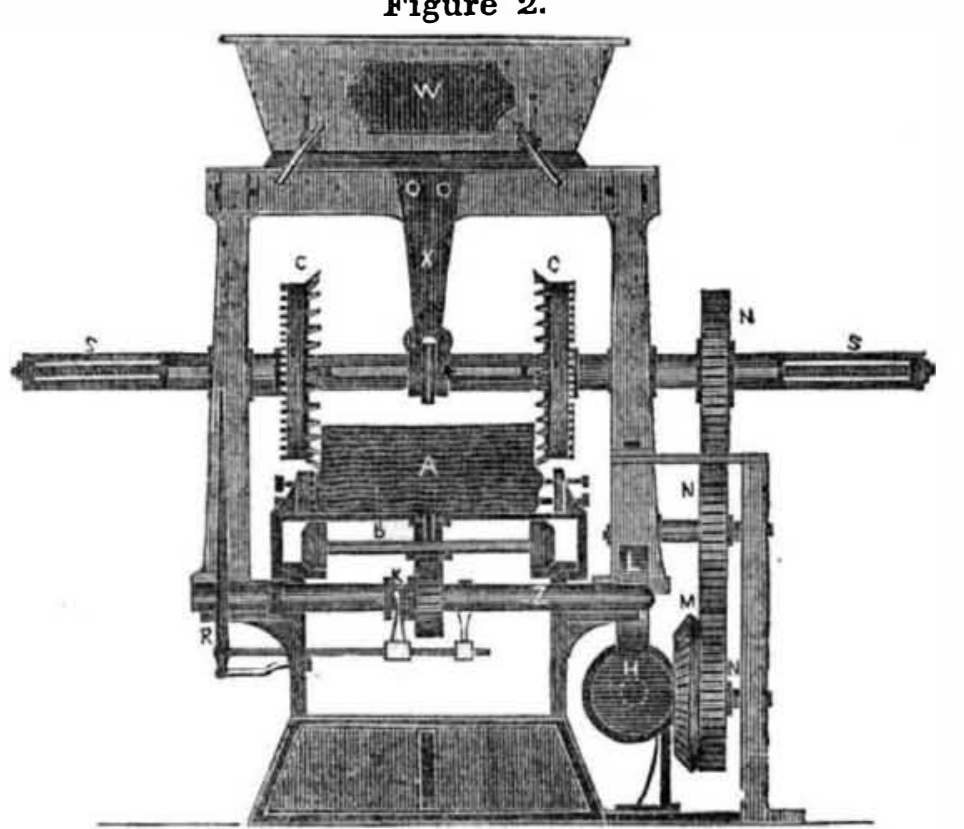

feathers each-one on each side. On the out : there are two, one on each side, both alike, er end is a nut fastened, which works a screw and the cutters set so that those of one wheel $\mathrm{S}$, which is made to shift the naves of the cut, pass alongside at the middle of the stone just ter wheels to any width required. The wheels after the other. The shaft $F$ is made to be set at move to cut at the front only; so that the an angle from the perpendicular line, sothat the machine, move off leaving it untouched seen in fig. 1 . This shaft is revolved by $\mathrm{J}$ a bethe machine, move off leaving it untouched
seen in fig. 1. This shaft is revolved by a be-
vel wheel on the main driver meshigg into $I$,

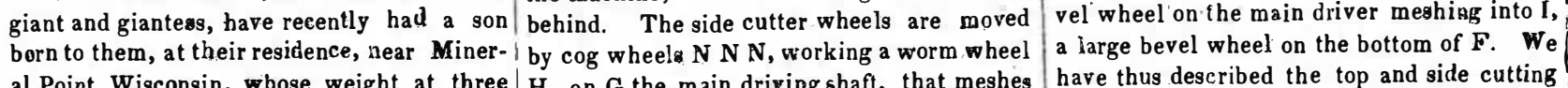

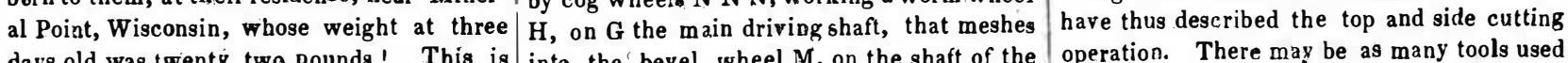
days old was twenty two pounds! This is into the bevel wheel M, on the shaft of the operation. There may be as many tools used

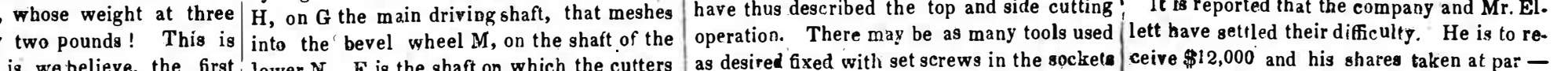

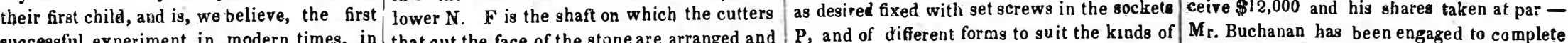

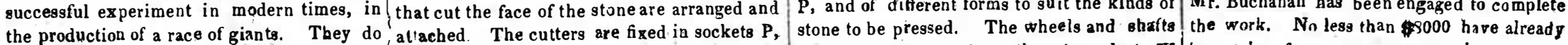

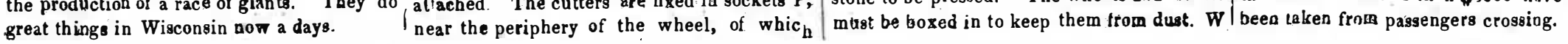
lished at the low rate of $\$ 1,50$, or two cents a mile. Two trains are advertised, leaving New Haven at 6 o'clock A. M. and 1 P. M., and leaving New York at $8 \mathbf{1}$ A. M. and at $3 \mathbf{k}$ P. M.

Tashville and Chateanooga Rallrond. We have received from $W$. $H$. Humphries, Esq. the first annual report of the efockhold era of this road. The report of the cbief. engineer is an able one. The whole route has been sarveyed, the points determined and ma. ny contracts made. It is to be hoped that Tennessee, so long and far behind our Eastern States in Ralroad enterprise, will now exhibit an energy and enterprise which will make up for lost time and character. lowered the price of travelling to $1 \frac{1}{2}$ cents per onile and the consequent inciease of travel has not only made up for the decrease, but the av erage income has been greater.

\section{Telegraph s.}

The British Government are going to lay telegraph wires across the Irish Channel, from Wales. This is certainly a great undertaking for the wires have to be laid in pipes in the bed of the sea, a distance of 60 miles.

The copying telegraph of $\mathbf{M r}$. Bain sends 400 letters per minute with a single wire from London to Slough.

Settlement of the Niagara Bridge Ques Setrement of the Nlagara Oriage Ques.
elon. It is reported that the company and $\mathrm{Mr}$. El.
.
This is a Stone Cutting Machine which we below revolving cutters, one set to cut the publish for the benefit of our subscribers and sides of the stone and anotherset to cut the those who are engaged in the stone cutting surface. The carriage may be made in two ble and will work well. It is public proper- $\mathbf{s w i n g}$ round if desired. The underside of

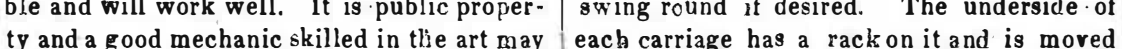
construct one similar to it from these draw. forvard by spur wheels gearing into said rack. \begin{tabular}{ll|l} 
construct one similar to it from these draw- & forward by spur wheels gearing into said rack. \\
ings. Wealthy companies who have large & Their may be a continuous rougd. of this gear-
\end{tabular} ings. Wealthy companies who have large Their may be a continuous rousd. of thisgear-
quarries would, we think, find it profitable to ing, so that the carriage may move continu. have such a machine, as it would no doubt bo ally round. $A$ is the stone in the carriage, a great saving for plain work. For ornamen- made firm by strong set screws $a a$, as seen in tal work it is not intended. In that branch fig. 2 . B is the carriage-a train of which is \begin{tabular}{ll|l} 
the head and the hand of the skilful work- & shown passing through the machine. $C$ are \\
man have as yet found no equal and never will & the two side cutting wheels. These wheels
\end{tabular} Drscriptron.-Fig. 1 is a side elevation are adjustable; the shafts are turned paralle 1 and 6g. 2 is an end view. The same letters and coupled at the middle suspended in the and 6g. 2 is an end view. The same letters
refer to like parts on both. The stones are carried forward in carriages, half their lengths, and have two broad strong

is a large water cistern above to be used if necessary. $E$ at the section post behind, may be a polisher driven by the same power to polish the stone in its progress, and finish them at one operation. 00 , is the bed fram. ing. It remains now to be explained how the carriages are moved. This is accomplished as allows: $H$ the worm wheel on the shaft $G$, meshes into $L$ and drives the cross shaft $\mathbf{Z}$, as seen in fig. 2 at the middle of which is a spur pinion that works the rack in the bottom of each carriage moving them forward. $R$, fig. 2 , is a lever which operates the clutch $K$, to stop the carriage at pleasure. Cutter wheels may also be arranged to cut the ends of the stones, and the serrated and pointed or that chisels may be very effectually used. For the cutting of heavy blocks, such a machine would be a great acquisition for rapid and cheap stone dressing. We know of no machine equal to one of this description in all respects, and the public are now both the judges of its merits and possessors of its principle.

$$
\text { RAR ROAD KE WS. }
$$

Hounatonic, wex York and wew Haves

An indignation meeting of the passengers who left Albany on Tuesday of last week was held the next day at the Harlem Ratiroad House in this city, expressing their disapprobation at the treatment they received from the everal companies. The cars were 24 hours on the route and they were delayed in one of the most bitter cold nights upon the road, nd at Harlem were left without fuel, fire or ights. Obe man almost perished from the effects of the cold and a number of females suffered severely.

New Iork and Rew Haven Helikand The first regular train from New York over is and and time of less was obstructed 4 hours, although the track New Haven is 76 miles. The fare is estab.

Most of the railroads in Great Britain have 